\title{
Pemberdayaan Kelompok Remaja dalam Pencegahan Perilaku Bullying di SMA X Baros Serang Banten
}

\author{
Evin Novianti, Duma Lumban Tobing \\ Prodi Keperawatan Fakultas IImu Kesehatan UPN Veteran Jakarta \\ Email: evinnovianti@upnvj.ac.id/08998203159
}

\begin{abstract}
Abstrak
Bullying merupakan perilaku agresif yang mengakibatkan tekanan pada pihak yang lebih lemah sehingga korban tidak mampu untuk membela dan mempertahankan dirinya. Selain itu penting untuk diperhatikan adalah bukan sekedar tindakan yang dilakukan, tetapi dampak tindakan tersebut bagi korban. Bullying dapat mengubah suasana sekolah yang awalnya menyenangkan, belajar sambil berteman, menjadi menakutkan bahkan mimpi buruk. perilaku bullying memiliki dampak negatif di segala aspek kehidupan. Tujuan pelaksanaan program kemitraan masyarakat ini adalah meningkatkan pengetahuan remaja akan dampak bullying dan cara pencegahannya. Program ini membantu remaja mencegah bullying serta mengatisipasi dampak lanjutan dari bullying sehingga terciptalah suasana akademik yang nyaman di sekolah. Metode pelaksanaan adalah dengan sosialisasi tentang bullying, dampak dan cara pencegahan kepada kelompok siswa SMAN X Baros. Melaui diskusi, melatih komunikasi asertif remaja ketika remaja berada di situasi sulit yaitu bullying. Telah terbentuk profil kelompok remaja tangguh di SMAN X Baros dengan motto "Kami Penerus Bangsa Siap Berkarya, SMAN X Baros Bebas Bully!!". Remaja berkomitmen untuk selalu menjaga sekolah mereka dari bullying. Terdapat perbedaan pemahaman akan bullying sebelum dan sesudah sosialisi, meningkat 5 point dengan $p$-value 0,000 . Meningkatnya kemampuan remaja untuk mengatasi bullying dapat melahirkan duta antibullying sehingga sekolah menjadi tempat yang nyaman dan kondusif.
\end{abstract}

Kata Kunci: Bullying; Remaja; Siswa SMA

\begin{abstract}
Bullying is aggressive behavior that results in pressure on the victim to be unable to defend and defend himself. In addition, it is important to note that it is not just the action that was taken, but the impact of the action on the victim. Bullying can change the school atmosphere that was initially fun, learning while making friends, into scary and even nightmares. Bullying has a negative impact in all aspects of life. The purpose of implementing this community partnership program is to increase adolescent knowledge of the impact of bullying and how to prevent it. This program helps adolescents prevent bullying and anticipate the aftereffects of bullying so as to create a comfortable academic atmosphere at school. The method of implementation is socialization about bullying, the impact and prevention methods to the group of students of SMAN $X$ Baros. Through discussion, train adolescent assertive communication when adolescents are in difficult situations, namely bullying. A profile of tough youth groups has been formed at SMAN X Baros with the motto "We are the Successors of the Nation, Ready to Work, SMAN X Baros is Bully Free !!". Teens are committed to always protecting their school from bullying. There are differences in understanding of bullying before and after socialization, increased by 5 points with a p-value of 0.000 . Increasing the ability of teenagers to cope with bullying can give birth to anti-bullying ambassadors so that schools become comfortable and conducive places.
\end{abstract}




\section{Keywords: Adolescence; Bullying; high school student}

\section{PENDAHULUAN}

Kesehatan mental remaja berhubungan erat dengan konsep diri, yang terbentuk dari pengalaman remaja dalam menyelesaikan masalahnya. Dengan kesehatan mental yang baik akan membentuk karakter remaja yang kuat terhadap problematika hidup di masa yang akan datang (Hurlock, 2014). Remaja mengalami masalah-masalah yang dapat menghambat tumbuh kembang secara psikologis dan berkontribusi terhadap pembentukan konsep dirinya, diantaranya adalah mendapatkan perlakuan bullying oleh teman sebaya sehingga berisiko munculnya ketidakpercayaan diri remaja menghadapi masa depan (Zakiyah, 2017).

Hasil wawancara dengan Kepala Puskesmas Desa Baros, pernah ditemukan kasus remaja mengalami bullying di sekolah. Informasi serupa juga didapatkan dari guru bimbingan konseling di SMAN X Baros, mengungkapkan bahwa masalah remaja yang muncul adalah penerimaan diri di lingkungan teman-temannya, remaja cenderung menunjukkan kuasanya di hadapan teman dengan menggunakan tenaga untuk menyudutkan orang lain sehingga mendapatkan pengakuan. 3 dari 10 remaja yang diwawancarai tim abdimas mengatakan bahwa cara-cara remaja menggunakan kekuatan adalah sesuatu yang biasa terjadi tanpa mereka tahu apa pengaruhnya terhadap kesehatan mental korban. Penerimaan bullying ini bisa berdampak buruk pada rendahnya prestasi belajar, sedangkan guru tidak mengetahui penyebab remaja menunjukkan perilaku malas ke sekolah dan penurunan akademik (Ttofi, 2011).

Remaja butuh penyegaran akan pengetahuan tentang apa saja faktor yang dapat menghambat prestasi mereka dan mempengaruhi tujuan mereka di masa yang akan datang yaitu masa dewasa muda (Mariyam, 2018). Keberhasilan seseorang di masa dewasa dipengaruhi kesuksesan menyelesaikan masalah di masa remajanya (Stuart \& Gail, 2016). Pengabdi melakukan berbagai kegiatan guna meningkatkan kemampuan berkomunikasi asertif remaja, pembentukan kelompok remaja anti bullying di SMAN X Baros, penambahan pengetahuan remaja tentang pentingnya menjaga kesehatan mental bersama-sama bagi kemajuan Desa Baros, pelatihan bagaimana cara bila melihat bullying, cara ketika mendapatkan bullying dan cara menjadi teman yang baik bebas bullying. Penjelasan tentang perlunya mengantisipasi hambatan pada perkembangan remaja terutama konsep diri, memberikan alasan yang cukup kuat bagi pengabdi untuk pentingnya melakukan kegiatan pemberdayaan masyarakat pada kelompok remaja ini. Tujuan pengabdian masyarakat adalah membentuk kelompok remaja sebagai Duta Anti Bullying di SMAN X Baros sehingga tercipta lingkungan belajar yang aman dan nyaman di sekitar remaja.

\section{BAHAN DAN METODE}

Metode kegiatan pengabdian masyarakat ini dilakukan dengan menggunakan pendekatan metode penelitian, untuk dapat membedakan hasil sebelum dan sesudah dilakukannya sosialisasi pengetahuan dampak bullying dan cara penanganannya. Kegiatan dimulai dengan survey lapangan, pengkajian di SMA X Baros berupa skrining bullying dengan angket kepada 140 siswa/i. Skrining yang telah diambil, dipilih sebanyak 30 orang siswa berdasarkan simple random sampling dan masukan dari guru pendamping sekolah dan selanjutnya tim mempersiapkan modul dan paparan yang berisi gambar dan handout sesuai kasus bullying. Metode diskusi dengan memberikan 
video interaktif tentang bullying untuk menarik perhatian remaja. Metode ini diberikan oleh tim pengabdi melalui studi kasus yaitu deskripsi situasi secara tertulis, rekaman audio, video ataupun foto yang kemudian dipelajari bersama-sama dan didiskusikan. Isi diskusi adalah mengenai pengertian bullying, dampak dan cara penanganannya. Pengabdi membagi peserta ke dalam lima kelompok kecil dan membuat motto anti bullying untuk sekolah mereka, yel-yel, puisi atau pantun tentang bullying. Hal ini dapat mengekspresikan perasaan remaja tentang bullying.

\section{HASIL}

Hasil skrining berdasarkan angket dan wawancara menunjukkan bahwa rata-rata remaja di SMAN X Baros berusia 15 tahun dengan usia terkecil 14 dan tertinggi 18 tahun. Rata-rata responden memiliki saudara kandung berjumlah 3 orang dengan saudara terbanyak adalah 12 orang dan tinggal dalam satu rumah rata-rata adalah 5-6 orang. 54\% remaja di SMAN X Baros masih nyaman untuk datang ke sekolah, hal ini merupakan peluang bahwa suasana akademik yang kondusif. Sebesar $41 \%$ remaja SMAN X Baros memiliki lebih dari 6 orang teman, artinya sebagian besar punya sumber pendukung bagi masalah remaja. Upaya untuk memaksimalkan sumber pendukung tersebut bisa tercapai dengan kerja sama antar siswa.

Remaja di SMAN X Baros mayoritas tidak pernah mengalami bullying, namun persentase 1-2x pernah dibully dalam sebulan sebesar 42,1\%, 2-3x dibully dalam sebulan $(1,4 \%)$ dan beberapa kali dalam seminggu $(5,7 \%)$ tidak boleh dianggap enteng. Pelaku bullying kerap melakukan memanggil nama korban dengan kasar $(52,1 \%)$, melakukan pengabaian (34,3\%), melakukan kekerasan fisik pada korban (17,9\%), memfitnah (40\%), mengambil barang berharga (30\%), melontarkan kalimat ancaman (32,1\%) dan meninggalkan pesan bernada ancaman $(15,7 \%)$ dapat berdampak pada korban atau bahkan pelaku itu sendiri.

Pengetahuan yang perlu diperbaiki adalah pernyataan bahwa pembenaran perilaku bullying didasarkan pada dendam dan dilampiaskan kepada peer groupnya. Sebanyak $16,7 \%$ remaja belum mengetahui bentuk bullying selain perlakuan kasar secara fisik. Bentuk Bullying non fisik terkadang luput dari perhatian remaja dan bahkan berdampak lebih besar daripada bullying fisik. Sebesar $40 \%$ remaja melakukan Bullying verbal seperti menyebarkan kebohongan atau fitnah, mencoba membuat orang lain tidak menyukai korban dan membuat lingkungan di sekitar korban menjadi tidak nyaman. Ada peluang positif dari kelompok remaja ini, bahwa $90 \%$ remaja telah mengetahui dampak bullying tidak hanya pada fisik saja tapi juga pada psikologis.

Efektifitas sosialisasi oleh pengabdi, dilihat dari nilai pre dan post pengetahuan remaja akan bullying, dengan menggunakan uji analisis t-dependent, diperoleh hasil bahwa pengetahuan remaja meningkat secara significant setelah sosialisasi bullying dengan $\mathrm{p}$-value $0,000(95 \% \mathrm{Cl}-4,882 ;-1,785)$. Pengetahuan remaja sudah termasuk dalam pengetahuan tinggi, mereka memiliki pemahaman yang baik tentang bullying.

\section{PEMBAHASAN}

Bullying mempunyai dampak bagi pelaku, dimana pelaku memiliki rasa percaya diri yang tinggi dengan harga diri yang tinggi pula, cenderung bersifat agresif dengan perilaku yang pro terhadap kekerasan, tipikal orang berwatak keras, mudah marah dan 
impulsif, toleransi yang rendah terhadap frustasi (Tumon, 2014). Remaja dengan bullying memiliki kebutuhan kuat untuk mendominasi orang lain dan kurang berempati terhadap targetnya. Dengan melakukan bullying, pelaku akan beranggapan bahwa mereka memiliki kekuasaan terhadap keadaan. Jika dibiarkan terus menerus tanpa intervensi, perilaku bullying ini dapat 3 menyebabkan terbentuknya perilaku lain berupa kekerasan terhadap anak dan perilaku kriminal lainnya (Sari, 2010).

Bullying memiliki dampak terhadap korban, dimana korban merasakan rasa cemas ketika berada dalam keadaan ramai, terisolasi, depresi bahkan dapat berakhir dengan bunuh diri. Namun, dampak bagi korban tidak langsung muncul pada saat terjadinya, emosi korban terpendam lama dan prosesnya secara perlahan, dan dalam jangka waktu yang panjang. Dampak akan terlihat beberapa tahun ke depan sehingga remaja tumbuh menjadi pribadi tidak percaya diri, sulit beradaptasi, peragu, tidak berani menatap masa depan dan sulit untuk berkompetisi. Pihak sekolah maupun orang tua bahkan korban tidak menyadari dampak tersebut (Silvia, 2018). Selain dari dampak psikologi yang ditimbulkan pada diri korban dampak fisik juga dapat terjadi seperti memar di daerah yang dipukuli oleh pelaku, lecet, bengkak, bahkan sulit untuk tidur dan nafsu makan menurun (Ikhsani, 2015).

Bullying menimbulkan rasa tidak nyaman remaja untuk datang ke sekolah, hal ini disebabkan oleh kurangnya rasa empati pelaku bullying, tidak memahami apa yang dirasakan dan tidak peduli terhadap korban. Penelitian yang dilakukan oleh Yandri (2013) menemukan bahwa munculnya pendapat di kalangan remaja bahwa perilaku mengejek, menyebutkan nama dengan nama binatang adalah suatu hal biasa dan wajar, namun tidak memperhatikan dampak yang ditimbulkan dari konsep diri korban. Tim abdimas menilai pentingnya meningkatkan rasa empati remaja terhadap korban bully.

Empati adalah kecenderungan untuk dapat memahami perasaan dan pikiran orang lain, memahami apa yang dirasakan orang lain. Seorang remaja yang punya rasa empati, memiliki rasa toleransi baik kepada sesama manusia (Anggraeni, 2013). Keterampilan sosial dan emosional pada remaja menjadi salah satu hal yang utama untuk dapat diarahkan agar remaja tumbuh menjadi seseorang yang berkompeten di lingkungan sosial sekolah serta menciptakan suasana akademik yang kondusif (Barker, 2010). Terciptanya suasana akademik yang kondusif, dipengaruhi oleh bagaimana persepsi remaja atau pemikiran remaja terhadap kejadian bullying di sekolah.

Aspek kognitif ini suatu kemampuan kognitif dalam memahami emosi korban. Pada aspek kognitif, seseorang harus dapat memahami reaksi korban, memberikan perhatian sepenuhnya kepada korban dan juga seseorang harus dapat memahami arti dari reaksi korban secara umum, makna dari situasi secara umum dan reaksi emosional yang muncul pada korban (Ahmad, 2017). Aspek afektif dalam hal ini proses emosi seseorang yang muncul baik dari sikap pikiran dan emosi yang muncul karena sadar ataupun tidak sadar, bereaksi langsung ketika melihat korban atau bisa disebut penularan emosi (Saiful, 2016). Dalam meningkatkan empati pada siswa proses meningkatkan empati ini dilakukan melalui edukasi.

Keterampilan sosial adalah suatu kemampuan untuk menunjukkan perilaku yang baik dan dinilai secara postif maupun negatif oleh lingkungannya, seseorang dengan keterampilan sosial ini agar dapat berkomunikasi secara efektif baik verbal maupun nonverbal dengan situasi dan kondisi ketika itu. Keterampilan sosial ini membawa 
seseorang untuk dapat mengungkapkan apa yang dirasakan dan permasalahan apa yang sedang dihadapi sehingga tidak menjadi sesuatu hal yang buruk menjadi tempat pelampiasan (Ranchman, 2018).

Keterampilan sosial remaja bisa dilihat dari beberapa aspek antara lain, hubungan dengan teman sebaya, manajemen diri, kemampuan akademis, kepatuhan terhadap peraturan dan dapat menempatkan diri dalam suatu kelompok atau lingkungan (Saptandari, 2013). Hubungan dengan sebaya ini sama halnya dengan sikap empati, jika hubungan seseorang dengan teman sebayanya baik maka teman sebaya tersebut bisa menjadi orang yang dapat melindungi korban agar terhindar dari tindakan kekerasan yang dilakukan oleh teman sepergaulan yang lainnya. (Hasan, 2013). Supaya setiap proses berlangsung dengan baik, maka penyampaian inovasi kepada Mitra ditempuh melalui tahapan penjelasan, diskusi, praktek serta dilakukan tahapan pendampingan.

\section{KESIMPULAN DAN SARAN}

Kesimpulan yang dapat ditarik dari hasil kegiatan abdimas pemberdayaan kelompok ini adalah Pembentukan profil kelompok remaja tangguh di SMAN X Baros dengan menciptakan motto sekolah yaitu "Kami Penerus Bangsa Siap Berkarya, SMAN $X$ Baros Bebas Bully!!". Dengan ini remaja berkomitmen untuk selalu menjaga sekolah mereka dari bully dan menurunkan generasi bebas bully. pemahaman remaja akan bullying meningkat dengan perhitungan menggunakan pendekatan metodologi riset, didapatkan adanya pengaruh peningkatan pengetahuan bullying setelah diberikan sosialisasi dengan $p$-value 0,000 . Meningkatnya kemampuan remaja untuk mengatasi bullying dapat melahirkan duta anti bullying sehingga remaja di SMAN X Baros menjadi lebih nyaman dan kondusif. Kemampuan yang meningkat diantaranya adalah mencari teman yang baik, mengenali masalah yang mungkin muncul dalam pertemanan dan cara berbicara asertif. Setelah diberikannya pemahaman akan bullying, perilaku anti bully akan disebarluaskan kepada teman di SMAN X Baros lainnya. Terdapat komitmen para siswa untuk terus menjaga suasana yang kondusif dan saling empati antar teman

\section{UCAPAN TERIMA KASIH}

Ucapan terima kasih peneliti berikan kepada Lembaga Penelitian dan Pengabdian Masyarakat UPN Veteran Jakarta atas pemberian dana pengabdian masyarakat yang dibebankan pada tahun anggaran 2020. Tim pengabdi juga mengucapkan terima kasih kepada pihak sekolah SMAN X Baros Serang Banten dan siswa/i yang telah bersedia menjadi duta anti bullying dalam pengabdian masyarakat ini. Tim pengabdi juga mengucapkan banyak terima kasih atas kesempatannya kepada Kecamatan Desa Baros dan Kepala Desa Baros pada awal peninjauan lapangan telah memberikan arahan dan ijinnya dalam bentuk surat mitra abdimas. 


\section{DAFTAR PUSTAKA}

Ahmad, S. 2017. Pengembangan modul bimbingan pribadi sosial untuk meningkatkan resiliensi Siswa Korban Bullying. Jurnal Psikologi Pendidikan Dan Konseling: Jurnal Kajian Psikologi Pendidikan Dan Bimbingan Konseling. https://doi.org/10.26858/jpkk.v0i0.3067

Anggraeni, D. T., Kumara, A., \& Utami, M. S. 2016. Validasi Program Remaja "STOP" (Sadar, Tolong, dan Perangi) Bullying untuk Mengurangi Intensi Perilaku Bullying pada Siswa SMP. Gadjah Mada Journal of Professional Psychology (Game JPP). https://doi.org/10.22146/gamajpp.33359

Barker, S. 2010. Psychiatric and Mental Health Nursing - The Craft of Caring, Second Edition. Journal of Psychiatric and Mental Health Nursing. https://doi.org/10.1111/i.1365-2850.2009.01521.x

[BPS] Badan Pusat Statistik. 2019. Berita resmi statistik. Bps.Go.Id.

Hasan, A. B. P., Firmiana, M. E., Sutiasmita, E., \& Rahmawati, S. 2013. Efektivitas Pelatihan Anti-Bullying terhadap Pengetahuan Penanganan Kasus Bullying di Sekolah pada Guru-Guru TK Jakarta. Jurnal Al-Azhar Indonesia Seri Humaniora. https://doi.org/10.36722/sh.v2i2.119

Hurlock, E. 2014. Perkembangan Anak Edisi Keenam Jilid I. Jakarta. In Penerbit Erlangga. https://doi.org/10.1078/0944-2006-00091

Ikhsani, Leliu Nurul. 2015.Studi Fenomenologi: dinamika psikologis korban bullying pada remaja. Fakultas Psikologi Universitas

Maryam, Siti;Fatmawati. 2018. Kematangan emosi remaja pelaku bullying. Jurnal Kajian dan Bimbingan. Asian Journal of Environment, History and Heritage September 2017, Vol. 1, Issue. 1, p. 211-222

Ranchman,Dzul'Al Syahrin,M.Najeri. 2018. Pelatihan komunikasi teman sebaya sebagai upaya meminimalisir bullying di Sekolah Menengah Atas Negeri. Jurnal Abdimas Mahakam. Online ISSN : 2549-5755.

Saifullah, Fitrian. 2016. Hubungan antara konsep diri dengan bullying pada siswa-siswa SMP. eJournal Psikologi Fisip Unmul. https://ejournal.psikologi.fisipunmul.ac.id/site/wpcontent/uploads/2016/02/ISI\%20eJournal\%20Psikologi\%20online\%20(02-1116-06-30-45).pdf

Saptandari, Ediburga Wulan;Adiyanti,M.G. 2013. Mengurangi bullying melalui program pelatihan "guru peduli". Jurnal psikologi UGM. https://jurnal.ugm.ac.id/ipsi/article/view/6977

Sari, P. 2010. Koping Stress Pada Remaja Korban Bullying di Sekolah " X ". Jurnal Psikologi. Volume 8(2): 75-81.

Silvia Yuliani1, Efri Widianti2, S. P. S. 2018. Resiliensi Remaja dalam Menghadapi Perilaku Bullying. Jurnal Keperawatan BSI

Stuart, G. W. 2016. Prinsip dan Praktik Keperawatan Kesehatan Jiwa. In International Journal of Social Psychiatry. https://doi.org/10.1177/0020764016675888

Tumon, M. B. A. 2014. Studi deskriptif perilaku bullying pada remaja. Jurnal IImiah Mahasiswa Universitas Surabaya. 
Ttofi, Maria M.;Farrington, David P. 2011. Effectiveness of school-based programs to reduce bullying: A systematic and meta-analytic review. Journal of experimental criminology.

Yandri, H., Daharnis, D., \& Nirwana, H. 2013. Pengembangan Modul Bimbingan dan Konseling untuk Pencegahan Bullying di Sekolah. Konselor. https://doi.org/10.24036/0201321866-0-00

Zakiyah, E. Z., Humaedi, S., \& Santoso, M. B. 2017. Faktor yang Mempengaruhi Remaja dalam Melakukan Bullying. Prosiding Penelitian Dan Pengabdian Kepada Masyarakat. https://doi.org/10.24198/jppm.v4i2.14352 


\section{LAMPIRAN}

Tabel 1. Distribusi Skrinning Remaja ( $n=140)$

\begin{tabular}{|c|c|c|c|c|}
\hline Variabel & Mean & Median & SD & Min-Max \\
\hline Usia & 15,73 & 16,00 & 0,900 & $14-18$ \\
\hline Anak ke & 2,97 & 3,00 & 1,791 & $1-9$ \\
\hline Jumlah saudara & 3,89 & 4,00 & 2,054 & $1-12$ \\
\hline
\end{tabular}

Tabel 2. Hasil Skrining Pengalaman Remaja Akan Bullying $(n=140)$

\begin{tabular}{|c|c|c|c|c|c|c|c|c|c|c|}
\hline \multirow{2}{*}{ Pernyataan } & \multicolumn{2}{|c|}{ Tidak pernah } & \multicolumn{2}{|c|}{$\begin{array}{l}1-2 x \text { dalam } \\
1 \text { bulan }\end{array}$} & \multicolumn{2}{|c|}{$\begin{array}{c}2-3 x \\
\text { sebulan }\end{array}$} & \multicolumn{2}{|c|}{$\begin{array}{l}1 \mathrm{x} \text { dlm } \\
\text { seminggu }\end{array}$} & \multicolumn{2}{|c|}{$\begin{array}{l}\text { bbrp kali dlm } \\
\text { seminggu }\end{array}$} \\
\hline & $\mathrm{n}$ & $\%$ & $\mathrm{n}$ & $\%$ & $\mathrm{n}$ & $\%$ & $\mathrm{n}$ & $\%$ & $\mathrm{n}$ & $\%$ \\
\hline Frekuensi dibully & 70 & 50,0 & 59 & 42,1 & 2 & 1.4 & 1 & 0,7 & 8 & 5,7 \\
\hline $\begin{array}{l}\text { (2) Memiliki nama } \\
\text { panggilan kasar, } \\
\text { dijadikan sebagai suatu } \\
\text { hal yang lucu, atau diejek } \\
\text { dengan cara yang } \\
\text { menyakitkan }\end{array}$ & 67 & 47,9 & 54 & 38,6 & 4 & 2,9 & 2 & 1,4 & 13 & 9,3 \\
\hline $\begin{array}{l}\text { (3) Siswa lain } \\
\text { meninggalkan saya } \\
\text { dengan tujuan tertentu, } \\
\text { mengeluarkan saya dari } \\
\text { kelompok, dan sama } \\
\text { sekali mengabaikan saya }\end{array}$ & 92 & 65,7 & 40 & 28,6 & 3 & 2,1 & 1 & 0,7 & 4 & 2,9 \\
\hline $\begin{array}{l}\text { (4) Dipukul, } \\
\text { ditendang, didorong, } \\
\text { atau dikunci di dalam } \\
\text { ruangan }\end{array}$ & 115 & 82,1 & 18 & 12,9 & 2 & 1,4 & 3 & 2,1 & 2 & 1,4 \\
\hline $\begin{array}{l}\text { (5) Siswa lain } \\
\text { menyebarkan } \\
\text { kebohongan atau fitnah } \\
\text { tentang saya dan } \\
\text { mencoba membuat } \\
\text { orang lain tidak } \\
\text { menyukai saya }\end{array}$ & 84 & 60,0 & 48 & 34,3 & 3 & 2,1 & 4 & 2,9 & 1 & 0,7 \\
\hline $\begin{array}{l}\text { (6) Uang atau } \\
\text { barang-barang saya } \\
\text { diambil dan dirusak }\end{array}$ & 98 & 70,0 & 37 & 26,4 & 1 & 0,7 & 2 & 1,4 & 2 & 1,4 \\
\hline $\begin{array}{l}\text { (7) Diancam atau } \\
\text { dipaksa untuk }\end{array}$ & 115 & 82,1 & 20 & 14,3 & 3 & 2,1 & 2 & 1,4 & 115 & 82,1 \\
\hline
\end{tabular}




\begin{tabular}{|l|c|c|c|c|c|c|c|c|c|c|}
\hline \multirow{2}{*}{ Pernyataan } & \multicolumn{2}{c|}{ Tidak pernah } & \multicolumn{2}{c|}{$\begin{array}{c}1-2 x \text { dalam } \\
1 \text { bulan }\end{array}$} & \multicolumn{2}{c|}{$\begin{array}{c}2-3 x \\
\text { sebulan }\end{array}$} & \multicolumn{2}{c|}{$\begin{array}{c}1 \times \text { dlm } \\
\text { seminggu }\end{array}$} & \multicolumn{2}{c|}{$\begin{array}{c}\text { bbrp kali dlm } \\
\text { seminggu }\end{array}$} \\
\cline { 2 - 11 } & $\mathrm{n}$ & $\%$ & $\mathrm{n}$ & $\%$ & $\mathrm{n}$ & $\%$ & $\mathrm{n}$ & $\%$ & $\mathrm{n}$ & $\%$ \\
\hline $\begin{array}{l}\text { melakukan sesuatu yang } \\
\text { tidak saya inginkan }\end{array}$ & & & & & & & & & & \\
\hline $\begin{array}{l}\text { (8) Diejek atau } \\
\text { dikomentari tentang ras } \\
\text { saya secara kasar }\end{array}$ & 95 & 67,9 & 31 & 22,1 & 6 & 4.3 & 4 & 2,9 & 4 & 2,9 \\
\hline $\begin{array}{l}\text { (9) Ejekan, } \\
\text { komentar, atau gerakan } \\
\text { kasar yang bermakna } \\
\text { seksual }\end{array}$ & 117 & 83,6 & 18 & 12,9 & 4 & 2,9 & 1 & 0,7 & 117 & 83,6 \\
\hline $\begin{array}{l}\text { (10) Pesan, telepon } \\
\text { atau gambar kasar dan } \\
\text { menyakitkan, atau cara } \\
\text { lain lewat telepon atau } \\
\text { internet }\end{array}$ & 118 & 84,3 & 19 & 13,6 & 2 & 1,4 & 1 & 0,7 & 118 & 84,3 \\
\hline
\end{tabular}

Tabel 3. Deskripsi Pengetahuan Remaja tentang Bullying sebelum Sosialisasi $(n=30)$

\begin{tabular}{|l|c|c|c|c|c|c|}
\hline \multicolumn{1}{|c|}{ Pengetahuan } & \multicolumn{2}{c|}{ Benar } & \multicolumn{2}{c|}{ Salah } & \multicolumn{2}{c|}{ Tidak tahu } \\
\hline \multicolumn{1}{|c|}{$\begin{array}{l}\text { Bullying merupakan perilaku negatif } \\
\text { seperti mencela dan mencelakai teman yang } \\
\text { dilakukan secara berulang sehingga } \\
\text { menyebabkan seseorang tidak senang atau } \\
\text { merasa tersakiti. }\end{array}$} & 30 & 100 & 0 & 0 & 0 & 0 \\
\hline $\begin{array}{l}\text { (2) Bullying adalah penggunaan } \\
\text { kekerasan, ancaman atau paksaan untuk } \\
\text { mengintimidasi orang lain. }\end{array}$ & 28 & 93.3 & 0 & 0 & 2 & 6.7 \\
\hline $\begin{array}{l}\text { (3) Ciri-ciri bullying adalah sering } \\
\text { berperilaku agresif, sengaja melakukan } \\
\text { kejahatan, dilakukan berkali-kali. }\end{array}$ & 28 & 93.3 & 2 & 6.7 & 0 & 0 \\
\hline $\begin{array}{l}\text { (4) Perilaku bullying dapat dilakukan } \\
\text { oleh semua orang. }\end{array}$ & 23 & 76.7 & 4 & 13.3 & 3 & 10. \\
\hline $\begin{array}{l}\text { (5) Seseorang melakukan bullying atas } \\
\text { dasar dendam atau iri hati, adanya } \\
\text { semangat ingin menguasai korban dengan } \\
\text { kekuatan fisik dan meningkatkan } \\
\text { popularitas pelaku dikalangan teman } \\
\text { sepermainan (preer group)-nya. }\end{array}$ & 28 & 93.3 & 2 & 6.7 & 0 & 0 \\
\hline $\begin{array}{l}\text { (6) Bullying dapat dilakukan oleh } \\
\text { seseorang atau kelompok yang biasa }\end{array}$ & 28 & 93.3 & 2 & 6.7 & 0 & 0 \\
\hline
\end{tabular}




\begin{tabular}{|c|c|c|c|c|c|c|}
\hline \multirow[t]{2}{*}{ Pengetahuan } & \multicolumn{2}{|c|}{ Benar } & \multicolumn{2}{|c|}{ Salah } & \multicolumn{2}{|c|}{ Tidak tahu } \\
\hline & $\mathrm{n}$ & $\%$ & $\mathrm{n}$ & $\%$ & $\mathrm{n}$ & $\%$ \\
\hline \multicolumn{7}{|l|}{ disebut dengan geng. } \\
\hline $\begin{array}{l}\text { (7) Pelaku bullying biasanya merupakan } \\
\text { seseorang yang mencari perhatian dari } \\
\text { banyak orang dan suka menimbulkan } \\
\text { permasalahan. }\end{array}$ & 24 & 80.0 & 0 & 0 & 6 & $\begin{array}{c}20 . \\
0\end{array}$ \\
\hline $\begin{array}{l}\text { (8) Ciri-ciri korban bullying antara } \\
\text { lain: korban cenderung pendiam, sulit } \\
\text { bergaul dengan yang lain. }\end{array}$ & 30 & 100 & 0 & 0 & 0 & 0 \\
\hline $\begin{array}{l}\text { (9) Jenis bullying yang dapat dilihat } \\
\text { dengan kasat mata dan terjadi sentuhan } \\
\text { fisik antara pelaku dan korban itu } \\
\text { merupakan jenis bullying fisik. }\end{array}$ & 28 & 93.3 & 2 & 6.7 & 0 & 0 \\
\hline $\begin{array}{l}\text { (10) Bullying verbal merupakan bullying } \\
\text { yang dapat terdetteksi lewat indera } \\
\text { pendengaran. }\end{array}$ & 26 & 86.7 & 0 & 0 & 4 & $\begin{array}{c}13 . \\
3\end{array}$ \\
\hline $\begin{array}{l}\text { (11) Perbuatan seperti membentak, } \\
\text { meledek, menghina, dan mencela } \\
\text { merupakan jenis bullying verbal. }\end{array}$ & 25 & 83.3 & 5 & 16.7 & 0 & 0 \\
\hline $\begin{array}{l}\text { (12) Memandang sinis, memandang } \\
\text { penuh ancaman, mendiamkan dan } \\
\text { mengucilkan merupakan jenis bullying } \\
\text { mental. }\end{array}$ & 27 & 90.0 & 0 & 0 & 3 & $\begin{array}{c}10 . \\
0\end{array}$ \\
\hline $\begin{array}{l}\text { (13) Pola asuh orang tua yang tidak baik } \\
\text { seperti orang tua yang selalu marah, } \\
\text { mengkritik bahkan memanjakan anaknya, } \\
\text { itu dapat menyebabkan perilaku bullying. }\end{array}$ & 19 & 63.3 & 5 & 16.7 & 6 & $\begin{array}{c}20 . \\
0\end{array}$ \\
\hline $\begin{array}{l}\text { (14) Seseorang yang hidup dikeluarga } \\
\text { yang salah satu anggota keluarganya sering } \\
\text { memukul atau menyiksa dapat } \\
\text { menyebabkan perilaku bullying. }\end{array}$ & 23 & 76.7 & 3 & 10.0 & 4 & $\begin{array}{c}13 . \\
3\end{array}$ \\
\hline $\begin{array}{l}\text { (15) Dampak bullying ini sangat } \\
\text { berbahaya jika tidak segera ditangani. }\end{array}$ & 28 & 93.3 & 0 & 0 & 2 & 6.7 \\
\hline $\begin{array}{l}\text { (16) Bullying dapat berdampak, seperti } \\
\text { kepercayaan diri yang rendah, mengasingkan } \\
\text { diri, menderita ketakutan sosial bahkan bisa } \\
\text { sampai melakukan bunuh diri. }\end{array}$ & 34 & 100 & 0 & 0 & 0 & 0 \\
\hline $\begin{array}{l}\text { (17) Bullying tidak hanya berdampak } \\
\text { secara fisik tetapi juga secara psikologis. }\end{array}$ & 27 & 90.0 & 0 & 0 & 3 & $\begin{array}{c}10 . \\
0\end{array}$ \\
\hline
\end{tabular}


Tabel 4. Analisis Pengetahuan Bullying Remaja Setelah Sosialisasi $(n=30)$

\begin{tabular}{|c|c|c|c|c|c|c|c|c|}
\hline $\begin{array}{c}\text { Pengetahuan } \\
\text { Bullying }\end{array}$ & Mean & Sd & SE & $\mathrm{t}$ & $\mathrm{df}$ & $\mathrm{p}$-value & \multicolumn{2}{|c|}{$95 \% \mathrm{Cl}$} \\
\cline { 1 - 4 } & & & & & & & Min & Max \\
\hline Pre & 30.67 & 4.147 & 0,757 & 4.403 & 29 & 0,000 & -4.882 & -1.785 \\
\hline Post & 34.00 & .000 & 0,000 & & & & & \\
\hline
\end{tabular}

